Pure Appl. Chem., Vol. 73, No. 8, pp. 1251-1255, 2001.

(C) 2001 IUPAC

\title{
Centre for Green Chemistry, Monash University, Australia*
}

\author{
Janet L. Scott ${ }^{1, \dagger}$, Colin L. Raston ${ }^{2}$, Christopher R. Strauss ${ }^{1}$, and \\ W. Roy Jackson ${ }^{1}$
}

${ }^{1}$ Centre for Green Chemistry, P.O. Box 23, Monash University, Melbourne, 3800, Victoria, Australia; ${ }^{2}$ School of Chemistry, University of Leeds, Leeds, LS2 9JT, UK

Abstract: The Centre for Green Chemistry is an Australian Research Council (ARC) Special Research Centre (SRC), located at Monash University in Melbourne, Australia. SRCs are funded by the Australian federal government, via the vehicle of the ARC, with the express goal of supporting excellent basic research and research training that has strong international links. The goal of the center is to provide a fundamental scientific base for future green chemical technology, identifying niche areas in the Australian context and beyond. Establishment of this SRC and its modus operandi are discussed.

\section{INTRODUCTION}

The Centre for Green Chemistry is an Australian Research Council (ARC) Special Research Centre (SRC), located at Monash University in Melbourne, Australia. Established in January 2000, the Centre is primarily located in the School of Chemistry at Monash University's Clayton campus and has links across Australia and internationally.

\section{ARC SPECIAL RESEARCH CENTRES IN CONTEXT}

The Australian Research Council (ARC) is the main funding agency in Australia for basic research. It supports research in essentially all fields from science, engineering, and new technologies through to social sciences, humanities, and the creative arts (except clinical medicine and dentistry) [1]. A recent policy statement (or "white paper") on research and research training outlines the policy and funding framework for higher education research and research training [2].

SRCs are funded by the Australian federal government via the Australian Research Council and are designed to "enable special concentrations of staff and resources for research and research training of a longer term nature" [3]. The centers are funded for up to 9 years, with reviews every 3 years, and 11 new centers were identified from 76 applications to receive funding beginning in 2000 [3]. Funding for these centers is AU\$13.2 million in 2000, AU\$29.9 million over the first three years of their operation, and AU\$135 million over their lifetime [4].

\footnotetext{
*Lecture presented at the IUPAC CHEMRAWN XIV Conference on Green Chemistry: Toward Environmentally Benign Processes and Products, Boulder, Colorado, USA, 9-13 June 2001. Other presentations are published in this issue, pp. 1229-1330.

Corresponding author
} 


\section{ESTABLISHMENT OF THE CENTRE}

\section{Events leading to the ARC SRC grant}

The chronology of events and their importance is summarized in Table 1.

Table 1 Events leading to the establishment of a Centre for Green Chemistry.

\begin{tabular}{|c|c|c|}
\hline Date & Event & Significance \\
\hline Feb 1998 & $\begin{array}{l}\text { Prof. T. Collins and Dr. P. Anastas address the } \\
\text { RACI, Professors and Head of Departments } \\
\text { meeting (PHODs) on the topic of green } \\
\text { chemistry }\end{array}$ & $\begin{array}{l}\text { Much apparent enthusiasm generated. Survey } \\
4 \text { months later indicated that the only action } \\
\text { taken was at Monash University. }\end{array}$ \\
\hline Jan 1999 & $\begin{array}{l}\text { Strategic Monash University Research Fund } \\
\text { (SMURF) grant for Green Chemistry* }\end{array}$ & $\begin{array}{l}\text { Monash University's commitment to green } \\
\text { chemistry research demonstrated }\end{array}$ \\
\hline Jan 1999 & $\begin{array}{l}\text { Introduction of green chemistry course into } \\
\text { undergraduate chemistry degree }\end{array}$ & $\begin{array}{l}\text { Demonstrates School of Chemistry and } \\
\text { Faculty of Science belief that green chemistry } \\
\text { issues are important educationally }\end{array}$ \\
\hline Jun 1999 & Application for ARC SRC submitted & $\begin{array}{l}\text { Includes extensive group of committed } \\
\text { researchers and extends beyond Monash } \\
\text { University }\end{array}$ \\
\hline Nov 1999 & ARC SRC grant awarded & $\begin{array}{l}\text { Reflects ARC acceptance of importance of } \\
\text { green chemistry research }\end{array}$ \\
\hline Jan 2000 & Centre for Green Chemistry established & $\begin{array}{l}\text { Significant financial input from Monash } \\
\text { University }\end{array}$ \\
\hline Jul 2001 & $\begin{array}{l}\text { Centre for Green Chemistry officially opened } \\
\text { by the Hon. K. Patterson, Senator for Victoria }\end{array}$ & \\
\hline
\end{tabular}

*Highest ranked proposal in funding round.

A key factor in driving the establishment of the Centre for Green Chemistry as an ARC SRC at Monash University was, undoubtedly, the presence of a dynamic "champion" of the idea. Prof. Colin L. Raston facilitated the address of the PHODs meeting of the Royal Australian Chemistry Institute (RACI) in 1998. While much enthusiasm was generated, there appeared to be little support for a national initiative in green chemistry, and a survey carried out four months later indicated no green chemistry initiatives other than that at Monash University. It was largely through direct contact with individual researchers and policy makers that Prof. Raston and, later, Prof. Jackson were able to generate significant support for the proposal of a Centre for Green Chemistry at Monash University.

A direct application for significant seed funding from the Strategic Monash University Research Fund (SMURF), which targets promising new research opportunities and development of faculty-nominated areas of potential research strength, was initiated and supported by a broad group within the School of Chemistry. Significant delivery in terms of successful, published research outcomes during 1999, provided added impetus for the ARC SRC application later in the same year. ARC SRC grants are hotly contested as the outcome, of significant funding for fundamental research for a number of years, is clearly highly desirable. This application, spearheaded by Raston and Jackson, competed against 76 other applications for 11 SRC grants and was rated extremely highly by the committee. 


\section{Strengths of the application}

\section{Breadth of the participants}

Named participants included 13 faculty members of the School of Chemistry, Monash University and prominent researchers from 4 divisions of CSIRO (Minerals, Forestry and Forestry products, Molecular Sciences, and Manufacturing Science and Technology) as well as associated researchers from other Australian universities.

\section{Merit of the research proposal}

The proposal included clear indications of the envisaged research areas, and many individual projects were already funded by existent ARC large grants, an indication of the creative and innovative nature of the research and the competitive capacity of the researchers.

\section{Convincing track records of the proposed Centre leaders}

The proposed Directors and Deputy Directors for the first six years of operation (Profs. Jackson, Raston, and Bond) have all been awarded (among other honors and awards) the RACI, H. G. Smith Award, which is the highest award for chemical research in Australia. Between them they are authors of more than 1000 refereed research papers, serve on numerous editorial boards (including that of the journal Green Chemistry), and have served as presidents of the RACI.

\section{Host institution support}

Monash University's support for the proposal was amply demonstrated in the allocation of funds for support of Green Chemistry Research and the Centre for Green Chemistry in the form of seed funds from the SMURF grant, creation of a lectureship and promise of significant funds for the salary of the director, and upgrading of existing buildings to create a new facility comprising laboratories, offices, and seminar room.

\section{Strong advisory board}

As the advisory board was envisaged to provide the Centre with guidance with respect to strategic directions it was essential that the board be broadly representative and have a high level of expertise both with respect to green chemistry and management. The board comprises representatives from senior university management, the Victorian Environmental Protection Agency (EPA), CSIRO management, the Plastics and Chemical Industry Association (PACIA), industry representatives and academic leaders in the field of green chemistry both from Australia and internationally. The relationship between the advisory board, management board, and director is illustrated in Fig. 1.

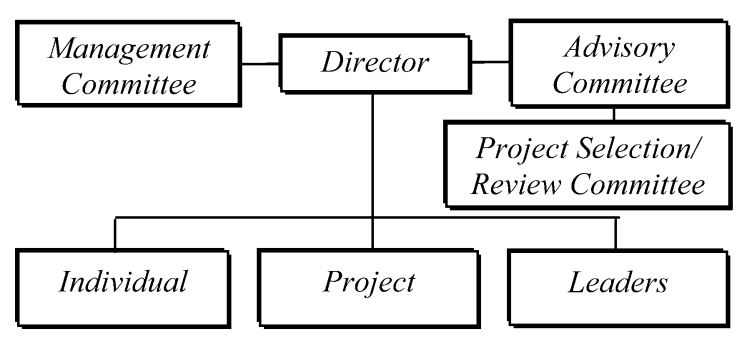

Fig. 1 Management structure of the Centre for Green Chemistry. 


\section{Good management and business plan}

A clear management structure in the form of a management committee was identified, as were project management mechanisms. The business plan was outlined, and the development of a long-term strategic plan flagged as an important part of the Centre's development.

\section{Clear milestones}

Milestones relating to publication output (and quality), external funding, levels of staffing and student numbers, and, importantly, industrial contacts were presented. These culminate in the financial independence of the Centre, which is essential for its continuation.

The proposal for the SRC also addressed a number of the themes incorporated in the "green paper" on higher education, research, and research training [5], and later used as a basis for the policy statement or "white paper" [2] released in December 1999. In particular, "strong strategic focus, enhanced collaboration with other participants in the research and innovation systems, and research training environments that are responsive to the needs of students and employers" were indicated.

\section{CURRENT STATUS}

The Centre has been in full operation for 18 months and now occupies its new facilities, which are already fully subscribed. The first annual report for the year 2000 [6] reflects strong growth in all key areas and output relative to milestones is satisfactory as reflected in Fig. 2.

There are currently $>20 \mathrm{Ph} . \mathrm{D}$. students associated with the Centre, and the number of associated researchers has also grown considerably with more collaborative projects developing, both nationally and internationally.

Educational initiatives extend from interactions with secondary school students via the "Community Outreach Programme" and CSIRO student research schemes, through undergraduate studies (sustainable chemistry course and research projects) to postgraduate studies (Ph.D. students and developing graduate courses in green and sustainable chemistry).

One of the major tasks for the period 2001-2002 is to develop a clear strategic plan for advancement toward the goal of financial self-sustainability and to focus on developing core competencies and expertise. Multidisciplinary skills and expertise are prerequisites for the Centre to be an effective base for advice and research in green chemistry, and the strategy for research conducted in the Centre involves a mix of projects and disciplines, objectives and durations, commercial collaborations, and arrangements for management of intellectual property.

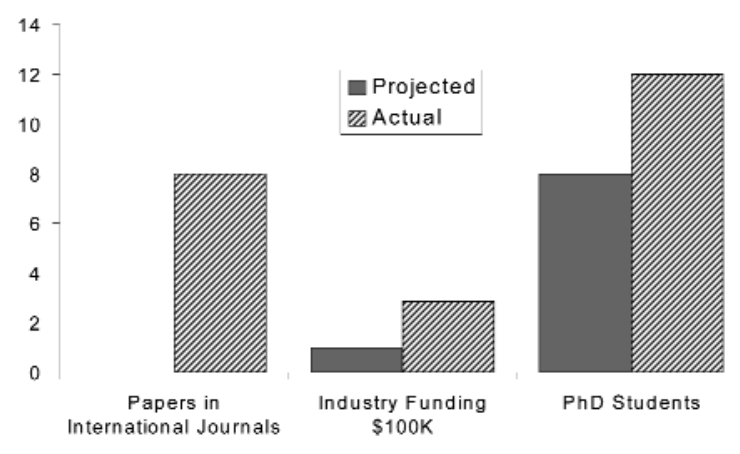

Fig. 2 Performance with respect to key year 1 milestones. 
To meet the aims of the Centre within the time frame, four main research streams have been identified to provide a suitable mix of: 1) fundamental research; 2) strategic research with unencumbered intellectual property (IP); 3) research for the public good; and 4) industrial collaborations. This is designed to provide a sustainable mix of: 1) new opportunities; 2) income-generating segments; and 3) high-profile fundamental scientific research, with the goal of providing the best possible research training for students and fulfilling the mission statement with regard to "becoming internationally recognised for research and teaching in the field of Green Chemistry" while ensuring the continued development of the Centre beyond the period of the ARC funding.

\section{REFERENCES}

1. Investing in Our Future, Australian Research Council Strategic Plan 2000-2002 (2000).

2. D. A. Kemp. Knowledge and Innovation: A policy statement on research and research training, (1999).

3. Australian Research Council. Discovery 3 (1999) http://www.arc.gov/newsletter/

4. Australian Research Council Annual Report, 1999/2000 (2000).

5. D. A. Kemp. New Knowledge, New Opportunities: A Discussion Paper on Higher Education, Research, and Research Training (1999).

6. ARC Special Research Centre for Green Chemistry, 2000 Annual Report (2000). 